Received: 24.07 .2019

Revised: 06.08.2019

Accepted: 30.08 .2019

DOI: $10.17804 / 2410-9908.2019 .4 .038-043$

\title{
OBTAINING PURE CARBON-ALLOYED NICKEL
}

\author{
S. E. Danilov ${ }^{a)^{*}}$ and V. L. Arbuzov ${ }^{\text {b) }}$ \\ M. N. Miheev Institute of Metal Physics, Ural Branch of the Russian Academy of Sciences, \\ 18 S. Kovalevskoy St., Ekaterinburg, 620990, Russian Federation \\ a) (iD https://orcid.org/0000-0001-9815-8196 danilov@imp.uran.ru; \\ b) (iD https://orcid.org/0000-0003-0334-7459 arbuzov@inm.uran.ru \\ *Corresponding author. E-mail: danilov@imp.uran.ru \\ Address for correspondence: ul. S. Kovalevskoy, 18, Ekaterinburg, 620990, Russian Federation \\ Tel.: +7 3433783850
}

The preparation of alloys with different carbon concentrations by diffusion annealing in a carburizing atmosphere using pure nickel (RRR at a level of 400) and homogenizing annealing in high vacuum is discussed. The installation scheme is described. The possibility of uniform carbon doping of samples and material in the form of 0.2 to $0.5 \mathrm{~mm}$ thick foils is shown in a wide range of concentrations ( 0.005 to 0.5 at. \%).

Carburizing annealing is carried out in an atmosphere of pure helium passed through a titanium getter with the addition of acetone vapor, which decomposes in the furnace and leads to coating the surface of the samples with carbon, which is a diffusion source. By choosing different temperatures and annealing times, various carbon concentrations or diffusion zones with known parameters can be obtained. The removal of surface layers in a polishing etchant after saturation and subsequent homogenizing annealing at high temperatures in high vacuum allow one to obtain a uniform distribution of carbon and a selected concentration.

Keywords: alloying, carbon, nickel, diffusion, carburization, homogenization.

\section{Acknowledgment}

The work was subsidized by the Complex Program of UB RAS, project No. 15-9-2-30.

\section{References}

1. Sorensen S.M., Chen C.W. The effect of carbon on void formation in neutron-irradiated nickel. Radiation Effects, 1977, vol. 33, pp. 109-118.

2. Begak O.Y., Fedorov V.V. Mass-spectrometric determination of low sulfur contents in metals by heterogeneous isotope equilibration. Journal of Analytical Chemistry of the USSR, vol. 37, iss. 5, pp. 661-664.

3. Shwerer F.C. Curie Temperatures and Residual Resistivity of Nickel-Carbon Solid Solution. J. Appl. Phys., 1969, vol. 40, no. 7, pp. 2705-2707. DOI: 10.1063/1.1658065. 
Подана в журнал: 24.07.2019

УДК 53.089

DOI: $10.17804 / 2410-9908.2019 .4 .038-043$

\title{
ПОЛУЧЕНИЕ ЧИСТЫХ СПЛАВОВ НИКЕЛЯ, ЛЕГИРОВАННЫХ УГЛЕРОДОМ
}

\author{
С. Е. Данилов ${ }^{\text {a)* }}$, В. Л. Арбузов ${ }^{\text {) }}$ \\ Федеральное государственное бюджетное учреждение науки \\ Институт физики металлов имени М.Н. Михеева Уральского отделения Российской академии наук, \\ д. 18, ул. С. Ковалевской, Екатеринбург, Российская Федераџия \\ a) (iD https://orcid.org/0000-0001-9815-8196 danilov@imp.uran.ru; \\ б) (iD https://orcid.org/0000-0003-0334-7459 arbuzov@inm.uran.ru \\ *Ответственный автор. E-mail: danilov@imp.uran.ru \\ Адрес для переписки: ул. С. Ковалевской, 18, 620990, Екатеринбург, Российская Федерация \\ Тел.: +7 (343) 378-38-50
}

Описано получение сплавов с различной концентрацией углерода путем проведения диффузионных легирующих отжигов в карбюризирующей атмосфере на примере чистого никеля (RRR на уровне 400) и гомогенизирующих отжигов в высоком вакууме. Описана схема установки. Показана возможность равномерного легирования углеродом образцов и материала в виде фольг толщиной на уровне 0,2-0,5 мм в широком диапазоне концентраций - $(0,005-0,5)$ ат. \% .

Карбюризирующий отжиг проводится в атмосфере чистого гелия пропущенного через титановый геттер с добавлением паров ацетона, разлагающегося в печи и приводящего к покрытию поверхности образцов углеродом, который является диффузионным источником. За счет выбора различных температур и времени отжига можно получать различные концентрации углерода получать диффузионные зоны с известными параметрами. Удаление поверхностных слоев в полирующем травителе после насыщения и последующий гомогенизирующий отжиг при высоких температурах в высоком вакууме позволяют получать равномерное распределение углерода и выбранную концентрацию.

Ключевые слова: легирование, углерод, никель, диффузия, карбюризация, гомогенизация.

\section{1. Введение}

При проведении исследований на сталях и сплавах по определению роли примесей в различных процессах, идущих при внешних воздействиях (облучение, деформация, термические процедуры и др.), часто возникает необходимость использовать образцы с известной концентрацией легирующей примеси при ее варьировании в широких пределах. При получении таких сплавов для чистоты эксперимента необходимо избежать или уменьшить до минимума проникновение в исследуемые образцы других примесей. Углерод является широко распространенной примесью в сталях и сплавах на основе никеля и железа и проникает в металл под действием различных термических процедур благодаря высокой диффузионной подвижности и хорошей растворимости. Поэтому часто возникает вопрос о его влиянии на изучаемые процессы.

B работе описана методика диффузионного приготовления сплавов $\mathrm{Ni}-\mathrm{C}$ из чистого никеля (RRR на уровне 400) в виде фольг толщиной 0,2-0,5 мм в широком диапазоне концентраций $(0,005-0,5)$ ат. \%. При этом проводится отжиг в карбюризирующей атмосфере, позволяющий провести легирование образцов до уровня предела растворимости углерода либо получение вблизи поверхности образцов диффузионной зоны, насыщенной углеродом, 
с последующим удалением части этой зоны и гомогенизацией оставшегося углерода в объеме образца путем отжига в высоком вакууме.

\section{2. Установка для легирования}

Установка для насыщения углеродом путем его осаждения на поверхности образцов при термическом разложении паров ацетона представлена схематически на рис. 1.

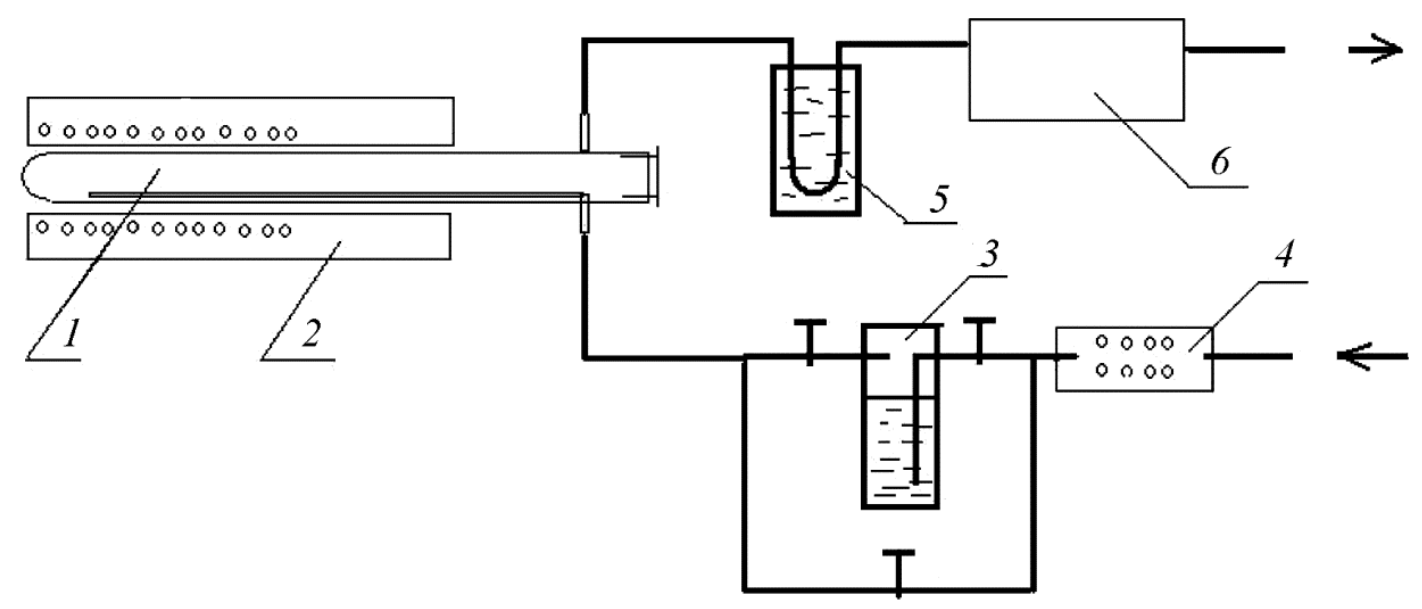

Рис. 1. Схема установки для карбюризирующего отжига. Кварцевая труба (1); печь (2); склянка Тищенко с ацетоном (3); титановый геттер (4); азотная ловушка (5); кислородомер (6)

Она представляет кварцевую трубу (1) с размещенными в ней образцами или пластинами исследуемого материала, помещенную в печь (2), с подведенной магистралью гелия или другого инертного газа, очищенного титановым геттером (4). Газ проходит через склянку Тищенко с ацетоном (3) либо мимо нее. Это определяется системой вентилей. На выходе из кварцевой трубы газ проходит через азотную ловушку (5) для отделения остатков углеводородов и кислородомер «Циркон-М» (6) для контроля работы титанового геттера. Первоначально гелий направляется по байпасной линии (мимо склянки Тищенко) до установления режима работы геттера очищающего гелий от кислорода и других газов, что контролируется по концентрации кислорода в пропускаемом газе. Скорость прокачки гелия около 0,5 л/мин. При нагревании кварцевой трубы до необходимой температуры (выше температуры разложения ацетона, около 870 К) с помощью вентилей поток очищенного газа перенаправляется через склянку Тищенко, где насыщается парами ацетона. Попадая в кварцевую трубу, ацетон разлагается с образованием мелкодисперсного углерода (сажи), который оседает на стенках трубы и на легируемых образцах, образуя тем самым углеродное покрытие, которое является диффузионным источником, по всей их поверхности. После окончания отжига оставшийся на поверхности образцов углерод легко удалить водой с моющим средством. Последующее электрохимическое удаление поверхностных слоев завершает очистку поверхности.

\section{3. Эксперименты и результаты}

Легирование может быть проведено двумя способами.

1. Насыщение углеродом до уровня равновесной концентрации, который определяется температурой отжига. При этом предел растворимости углерода в никеле, согласно выражению [1]:

$$
C_{\mathrm{C}}(\text { ат. } \%)=60,657 \exp \left(-\frac{5160}{T}\right)
$$


где $C_{\mathrm{C}}$ - предел растворимости углерода в никеле при температуре $T$. Длительность отжига определяется из условия приблизительного завершения равномерного распределения углерода по образцу:

$$
\sqrt{D t}>l
$$

где $l$ - толщина образца; $t$ - время легирующего отжига; $D$ - коэффициент диффузии углерода в никеле при температуре $T$, согласно выражению [2] ( $\mathrm{cm}^{2} /$ сек):

$$
D=2,5 \exp \left(-\frac{20100}{T}\right) \text {. }
$$

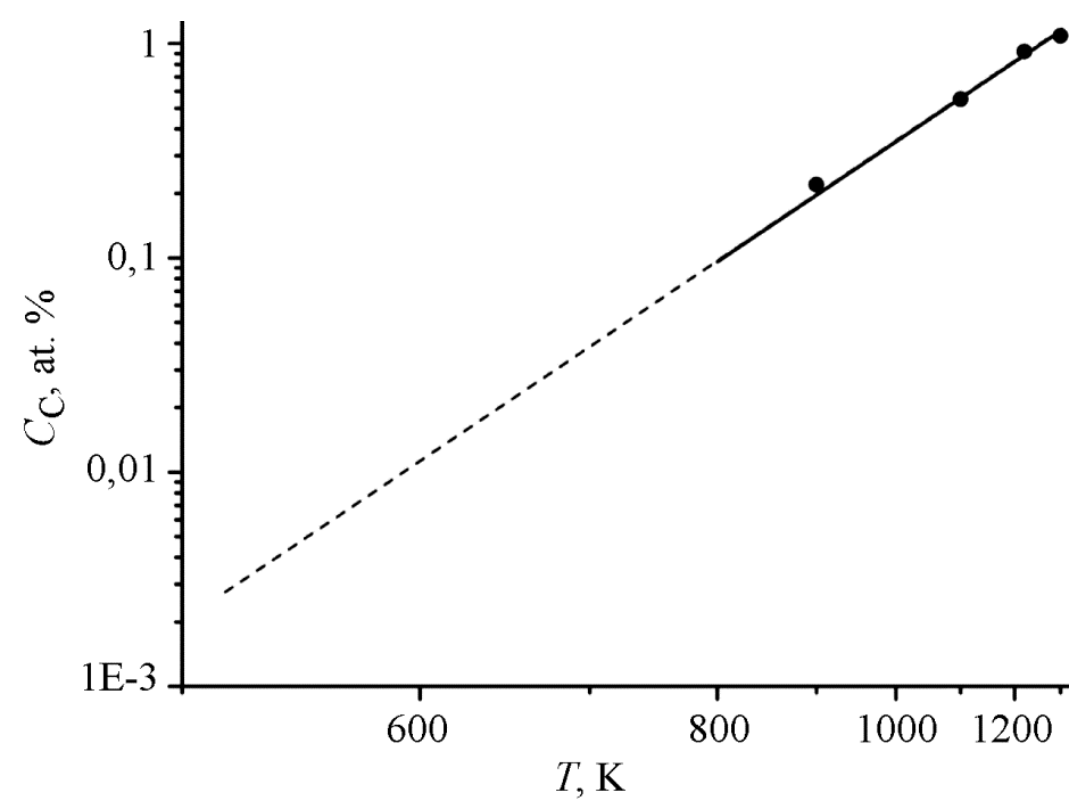

Рис. 2. Зависимость растворимости углерода в никеле [1] (сплошная линия); и экспериментально полученные значения (круглые точки) при насыщении первым способом; экстраполяция зависимости к низким температурам (пунктирная линия)

На основании этой зависимости был построен график (рис. 2).

Например, для получения концентрации углерода 0,5 \% по этому способу образцы толщиной около 200 мкм насыщались углеродом при температуре 1090 К в течении 5 ч.

Для получения низких концентраций углерода этот способ мало пригоден, поскольку соответствующие температуры отжига существенно ниже и при этом сильно увеличивается необходимое время отжига.

2. Для приготовления сплавов с более низкими концентрациями (меньше 0,1\%) насыщение проводилось вторым способом, который заключается в создании диффузионной зоны углерода в районе поверхности образца при карбюризирующем отжиге выше $870 \mathrm{~K}$ с последующим удалением поверхностного слоя рассчитанной толщины путем полирующего электрохимического травления. 


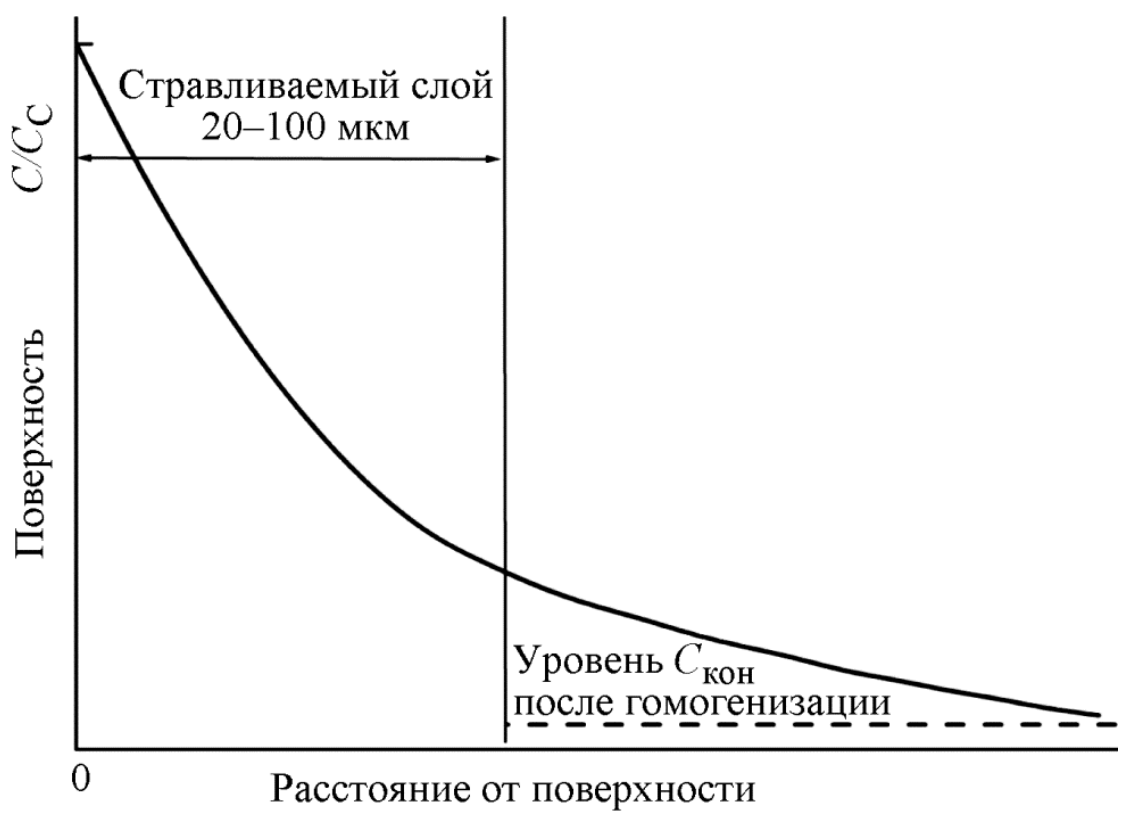

Рис. 3. Схематическое изображение получающегося при насыщении углеродом диффузионного профиля у поверхности никеля и удаляемого травлением поверхностного слоя

При этом в образцах оставалось некоторое количество углерода в приповерхностных областях. В дальнейшем образцы отжигались при температурах в интервале 1000-1100 K в безмасляном вакууме лучше чем $10^{-5}$ Па для создания гомогенного распределения углерода. На рис. 3 представлен график получающегося при насыщении углеродом диффузионного профиля. На поверхности образцов концентрация углерода равна пределу растворимости $C_{\mathrm{C}}$ при температуре отжига. Варьируя температуру и время легирующего отжига, можно получать различные диффузионные зоны у поверхности. Диффузионный профиль для одномерной диффузии из плоского источника легко получить из известных формул. Изменяя толщину стравливаемого с поверхности слоя и производя после этого гомогенизирующий отжиг в вакууме, можно получать различные концентрации углерода

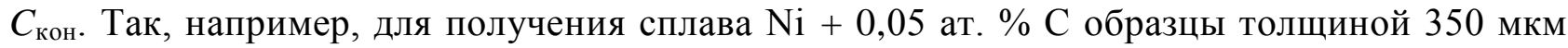
отжигали в установке (рис. 1) при $T=910 \mathrm{~K}, 15$ мин, а толщина удаляемого после этого слоя путем электрохимического травления составляла 100 мкм. Скорость удаления слоев при травлении легко оценить из результатов предварительных оценочных опытов конкретно на имеющейся электрохимической ячейке.

В данной работе концентрация углерода в никеле после гомогенизации определялась методом измерения остаточного электросопротивления. В работе [3] был определен вклад углерода в электросопротивление никеля при гелиевой температуре как $(3,48 \pm 0,06)$ мкОм·см. Для оценок, при условии отсутствия загрязнения, это позволяет успешно и оперативно контролировать процессы насыщения. Для более точного установления концентрации углерода необходимо учитывать отклонение от правила Матиссена [3]. Естественно, что для корректных процедур насыщения необходимо проведение контрольных отжигов, исключающих этап насыщения углеродом. Такие отжиги в нашем случае для чистого никеля давали отношение электросопротивлений на уровне 200-300, что соответствует отсутствию загрязнений выше 0,005 ат. \% углерода.

Метод применим для насыщения углеродом также и других металлов и сплавов, в которых углерод достаточно подвижен и известны параметры диффузии и растворимость углерода. 


\section{Благодарность}

Работа выполнена на средства субсидии, выделенной на финансирование проекта Комплексной программы Уральского отделения РАН 15-9-2-30.

\section{Литература}

1. Sorensen S. M., Chen C. W. The effect of carbon on void formation in neutron-irradiated nickel // Radiation Effects. - 1977. - Vol. 33. - P. 109-118.

2. Begak O. Y., Fedorov V. V. Mass-spectrometric determination of low sulfur contents in metals by heterogeneous isotope equilibration // Journal of Analytical Chemistry of the USSR. Vol. 37, iss. 5. - P. 661-664.

3. Shwerer F. C. Curie Temperatures and Residual Resistivity of Nickel-Carbon Solid Solution // J. Appl. Phys. - 1969. - Vol. 40, no. 7. - P. 2705-2707. - DOI: 10.1063/1.1658065. 